\title{
The impact of natural events and disasters on the Australian stock market: A GARCH-M analysis of storms, floods, cyclones, earthquakes and bushfires
}

\author{
Andrew C. Worthington \\ School of Accounting and Finance, University of Wollongong, \\ Wollongong, NSW 2522, Australia \\ E-mail: andreww@uow.edu.au
}

\begin{abstract}
This paper examines the impact of natural events and disasters in Australia on Australian stock market returns. The data set employed consists of daily price and accumulation (including dividends and changes in capitalization) returns from 1 January 1980 to 30 June 2003 and the complete timing and duration of all severe storms, floods, cyclones, earthquakes and bushfires recorded during this period. A GARCH-Mean model is used to model the return series and the natural events and disasters are specified as exogenous explanatory variables. The results indicate that at the market level, natural events and disasters have no significant impact on returns however defined.

Keywords: Natural events, disasters and catastrophes, return volatility, exogenous variables, GARCH

Biographical note: Andrew Worthington is Professor of Finance and Head of the School of Accounting and Finance at the University of Wollongong. His previous appointments include the University of New England and the Queensland University of Technology. He holds Masters from the University of New South Wales and the University of New England and received his doctorate from the University of Queensland.
\end{abstract}

\section{Introduction}

In recent years, and for all too understandable reasons, public concern regarding events and disasters of a natural origin has fallen relative to those of human origin. However, natural events and disasters (including floods, storms, bushfires, hurricanes, cyclones, tsunamis and earthquakes) continue to cause severe and increasing damage to global economies. In the United States the average annual loss from natural disasters in the period 1989 to 1993 was USD3.3 billion, and this grew to USD13 billion annually over the four years to 1997 (Federal Emergency Management Agency, 2003). At least part of this increase is attributed to global climate change (and its influence on hurricane, flood and tornado activity) and part to population growth in disaster-prone states (including hurricanes in Florida, North Carolina and Texas and earthquakes in California and Washington).

Similarly, in Australia the average annual cost of natural disasters between 1967 and 1999 was AUD1.14 billion (including the cost of deaths and injuries) and there is also some 
evidence that the number and costs of disasters per year are increasing, partly due to better reporting and possibly also to increasing population and infrastructure in vulnerable areas (Emergency Management Australia, 2003). Such developments are reflected on a global scale, where economic and financial activity is very often concentrated in areas prone to natural hazards, led most notably by Tokyo, the San Francisco Bay area, the combined OsakaKobe-Kyoto mega city and Miami (Anonymous, 2003). In response to these developments, an emerging literature has addressed a variety of dimensions regarding the economic and financial impact of natural disasters including Fox (1995, 1996), Zeckhauser (1996), Skidmore and Toya (2002), Horwich (2000), Albala-Bertrand (2000) and Skidmore (2001).

In brief, the estimated economic costs of natural events and disasters depend on the level at which the analysis is undertaken. At its broadest, and apart from the direct damage caused to those in the affected area, the disruption to supply caused by a natural disaster usually involves the transfer of producer surplus from those enterprises negatively affected to those that are unaffected. As these transfers do not normally comprise economic loss (unless new supply is sourced from imports or the original supply was intended for export, in which case the transfer of producer surplus is from domestic to foreign producers) the economic analysis of natural events and disasters ignores the distributional effects and concentrates on all other impacts affecting any member of society (Bureau of Transport Economics, 2001). These impacts may be both tangible (with market values) and intangible (without market values). In the former, they include direct costs such as the damage to infrastructure, buildings and vehicles and indirect costs from the loss of production, emergency response, relief and cleanup. In the latter, they include the direct costs from death and injury and the destruction of items of cultural and personal significance and indirect costs from inconvenience, social disruption and the stress associated with mortality and illness (Bureau of Transport Economics, 2001). Depending on the type of disaster, it is often found that intangibles comprise the largest part of the total costs of a given event.

In contrast to the economic analysis of natural disasters, financial analysis is concerned solely with the financial impact on those individuals and enterprises directly affected [see, for instance, Sprecher and Pertl (1983), Davidson et al. (1987), Antoniou et al. (1998), Miller (1991), Thompson et al. (1994) and Chien and Siems (2002)]. Here market prices are used to value all costs and benefits and all other impacts outside these entities are ignored. It is within this limited context that most of the existing financial research into natural disasters is placed and which, for the most part, has focused almost primarily on the property-liability insurance industry. Within this industry, two opposing, but not mutually exclusive, hypotheses exist [see 
American Academy of Actuaries (2001) for a discussion of insurance industry catastrophe management practices]. The first and most obvious is that insurers, because of the payments made to policyholders for their damages, incur large losses. While at least some of this is offset by reinsurance, for the most part the expectation is that these losses should cause insurance stocks to decline at the time of the disaster. The less obvious effect is that insurers benefit from an isolated catastrophic event because of increased demand for their products, through an increase in both required coverage and additional premium earnings.

The net effect on property-liability insurer stock values thus varies according to the relative strength of these two opposing forces. Shelor et al. (1992) and Aiuppa et al. (1993), for example, both concluded that insurer stock values increased after California's Loma Prieta earthquake [insured loss USD2.5 billion] in part because high earthquake insurance rates and low perceived risk meant many property owners were uncovered at the time. Conversely, Angbazo and Narayanan (1996) and Lamb (1995) found that the large negative effect of Florida and Louisiana's Hurricane Andrew [insured loss USD16.5 billion] was only slightly offset by the subsequent premium increases, and furthermore that the event even showed evidence of a contagion effect to insurers with no claims exposure in the hurricane affected states. Lastly, Cagle (1996) concluded that South Carolina's Hurricane Hugo [insured loss USD4.2 billion] caused a significant negative price reaction for insurers with high exposure and unaffected those with low exposure. The issue of property catastrophe risk and insurance/reinsurance is discussed at length in Borden and Sarker (1996), Jones (1999) and Anderson (2000).

It is clear, even putting aside the intrinsically narrow focus of financial analysis into natural events and disasters, that existing research suffers a number of limitations. First and foremost, there is the concentration on the property liability insurance industry even though it is well known that natural events and disasters have a substantial, often positive, impact on non-insurance firms (Bureau of Transport Economics, 2001; Federal Emergency Management Agency, 2003; Emergency Management Australia, 2003). For instance, Skidmore and Toya (2002) discuss how the impact of natural disasters is normally felt first in the loss of capital and durable goods and that efforts to replace them (such as by the construction and manufacturing industries) often increase economic output. Moreover, insured losses always underestimate total losses by a significant margin. For example, in Australia the proportion of insured to total loss is only 35 percent for severe storms and bushfires, 25 percent for earthquakes, 20 percent for tropical cyclones and as little as 10 percent for floods. No study 
currently exists which examines the impact of natural events and disasters across an entire market.

Second, nearly all past studies of the financial impact of natural events and disasters have tended to employ a single event study. While this simplifies the analysis, it is problematic in that single events may be susceptible to contamination by macroeconomic events independent of the disaster or catastrophe itself. For example, West (2003) argues that the Shelor et al. (1992) analysis of the 1989 Loma Prieta earthquake was compromised because it failed to take account of the lowering of official interest rates two days later. Even so, the distinction (usually on the basis of insured cost) between natural 'catastrophes', 'disasters' and 'events' is arbitrarily made and often ignores the fact that even relatively 'small' episodes can have important financial impacts. This is especially the case where a series of such events and disasters occur in quick succession. Unfortunately, no evidence currently exists on how the ongoing sequence of natural events and disasters, both large and small, impacts upon market behavior.

Accordingly, the purpose of this paper is to model the financial market effects of the complete recent historical record of natural events and disasters in Australia. This is believed to be the first study of natural disasters to use ARCH modeling, and one of few studies of the financial impacts of natural disasters outside the United States. The paper itself is divided into four main areas. The second section explains the data employed in the analysis and presents some summary statistics. The third section discusses the methodology employed. The results are dealt with in the fourth section. The paper ends with some brief concluding remarks.

\section{Data and summary statistics}

Two sets of data are employed in the analysis. The first set is the daily closing price for the Australian Stock Exchange All Ordinaries index over the period 1 January 1980 to 30 June 2003. The All Ordinaries is a market-weighted index accounting for about ninety-six percent of the market capitalization of domestic equities listed in Australia. The criteria for inclusion in the index place an emphasis on liquidity and investability and together the high frequency of information arrivals and volume of trading in these securities are likely to reduce measurement error problems. All data is obtained electronically from Bloomberg. The natural $\log$ of the relative price is computed for the 6,130 closing prices to produce a time series of continuously compounded daily returns, such that $r_{t}=\log \left(p_{t} / p_{t-1}\right) \times 100$, where $p_{t}$ and $p_{t-1}$ represent the market price at time $t$ and $t-1$, respectively. Both price and accumulation 
(including dividends and capitalization changes) indices are used yielding a daily price and accumulation return series.

The second set of data is sourced from Emergency Management Australia. Emergency Management Australia (2003) provides a database that is a record of Australian natural disasters compiled using estimates from insurance industry bodies, published disaster reports and articles in newspapers and other media. The database relies heavily on media reports and therefore the consistency of the media's approach and its definitions as to what constitutes a newsworthy event are a major limitation (Bureau of Transport Economics, 2001). Nevertheless, the database is believed to constitute the most complete record of natural disasters in Australia. Since the emphasis in this analysis is on the market effects irrespective of magnitude, the information used to categorize each natural event or disaster is restricted to its timing, duration and broad geographic location, for which dummy variables are employed.

Five major categories of disaster are identified from the most common forms of natural events and disasters in Australia. These are: (i) severe storms (including hail); (ii) floods (including flash floods); (iii) tropical cyclones (including tornados and sea spouts); (iv) bushfires (or wildfires); and (v) earthquakes (including landslides). Between 1967 and 1999 floods (28.9 percent of average annual cost) were the most costly and frequent disaster type in Australia, followed by severe storms (26.2 percent) and tropical cyclones (24.5 percent). Though bushfires are also frequent, they are generally less costly (7.1 percent), but more hazardous in terms of deaths and injuries. Earthquakes, on the other hand, are less frequent but have been significant in terms of costs (13.3 percent), largely through a single event (the 1989 Newcastle earthquake) (Bureau of Transport Economics, 2001). The other disaster categories also include relatively more costly single events, such as the Sydney hailstorm and Ash Wednesday bushfires. The duration of these events vary, with earthquakes and, to a lesser extent, cyclones and severe storms confined to a single day, while bushfires and floods occur over several days, weeks or even months. On this basis, it is expected that the initial impacts of earthquakes and severe storms will be more pronounced than other types of event or disaster that persist over a longer period.

The geographic location of each event or disaster is also included. The next set of information then comprises six dummy variables reflecting the state of location: namely, New South Wales, Victoria, Queensland, South Australia, Western Australia and Tasmania. The justification behind these measures is that the characteristics of the types of natural events and disasters possible depend heavily on location, as do the costs and prospective impacts on the Australian equity market. For example, both the frequency and costs of natural disasters are 
highest in the first and third most populous states of NSW and Queensland in much the manner as Texas, California and Florida record the highest disaster totals in the United States (Federal Emergency Management Agency, 2003). Similarly, some types of events and disasters are frequent in some states and unknown in others. For instance, the major sources of natural disaster costs are severe storms in NSW, tropical cyclones in the Northern Territory (included with the Australian Capital Territory as the control variable) and Western Australia, floods in Victoria, South Australia and Queensland and bushfires in Tasmania (Bureau of Transport Economics, 2001).

\section{<TABLE 1 HERE $>$}

Table 1 presents the descriptive statistics of the daily market returns and the natural event/disaster dummy variables. Sample means/proportions, standard deviations, skewness, kurtosis and the Jacque-Bera statistic and $p$-value are reported. By and large, the distributional properties of both return series appear non-normal. Both are negatively skewed (-4.9145 and 4.9769), indicating the greater probability of large deceases in returns than rises (that is, volatility clustering in daily returns). The asymptotic sampling distribution of skewness is normal with mean 0 and standard deviation of $\sqrt{6 / T}$, where $T$ is the sample size. Since the sample size for the return series is 6,130 then the standard error under the null hypothesis of normality is 0.0312: the estimates of skewness are significant at the .01 level. The kurtosis, or degree of excess, in both return series is also large (142.4131 and 143.5288), thereby indicating leptokurtic distributions. Given the sampling distribution of kurtosis is normal with mean 0 and standard deviation of $\sqrt{24 / T}=0.06257$, then the estimates are once again statistically significant at any conventional level. The Jarque-Bera statistics and corresponding $p$-values in Table 1 are used to test the null hypotheses that the daily distribution of market returns is normally distributed. Both $p$-values are smaller than the .01 level of significance suggesting the null hypothesis can be rejected. These stock market returns are then not well approximated by the normal distribution.

The descriptive statistics for the natural disaster dummy variables are also included in Table 1. Each corresponds to a day on which a particular event or disaster is recorded and therefore the duration varies across the different disaster types. Of the disasters examined, bushfires, floods and severe storms were the most common type of event/disaster recorded (as a percentage of total days in brackets) with 820 (13.38 percent), 691 (11.27 percent) and 473 (7.72 percent) daily episodes. Earthquakes and cyclones only accounted for 311 and 17 
days or 5.07 and 0.28 percent of days, respectively. Across the states the most natural events and disasters were recorded in Western Australia (679 or 11.08 percent), followed by New South Wales (603 or 9.84 percent), Queensland (535 or 8.73 percent) and Victoria (284 or 4.63 percent). All of the natural event and disaster dummy variables are significantly positively skewed indicating the proportionally lower likelihood of these events.

\section{Model specification}

The descriptive analysis of Australian market returns is suggestive of non-normality and ARCH behavior. A formal Lagrange multiplier test rejects the null hypothesis of no ARCH errors in favor of the alternative that the conditional error variance is given by an ARCH process $($ statistic $=6.951, p$-value $=0.000)$. These distributional properties indicate that generalized autoregressive conditional heteroskedastistic (GARCH) models can be used to examine the dynamics of the return generation process.

The specific $\operatorname{GARCH}(p, q)$-M model used is considered appropriate for several reasons. First, the capital asset pricing model (CAPM) and the arbitrage pricing theory (APT) establish the well-known (positive) relationship between asset risk and return. At a theoretical level, asset risk in both CAPM and APT is measured by the conditional covariance of returns with the market or the conditional variance of returns. ARCH models are specifically designed to model and forecast conditional variances and by allowing risk to vary over time provide more efficient estimators and more accurate forecasts of returns than those conventionally used to model conditional means.

Second, an approach incorporating $\operatorname{GARCH}(p, q)$ can quantify both long and short-term memory in returns. While ARCH allows for a limited number of lags in deriving the conditional variance, and as such is considered to be a short-term memory model, GARCH allows all lags to exert an influence and thereby constitutes a longer-term memory model. This reflects an important and well-founded characteristic of asset returns in the tendency for volatility clustering to be found, such that large changes in returns are often followed by other large changes, and small changes in returns are often followed by yet more small changes. The implication of such volatility clustering is that volatility shocks today will influence the expectation of volatility many periods in the future and $\operatorname{GARCH}(p, q)$ measures this degree of continuity or persistence in volatility.

The GARCH( $(p, q)-\mathrm{M}$ model is described by the following: 


$$
\begin{aligned}
& r_{s, t}=\alpha_{s, k} \sum_{k=1}^{n} x_{s, k}+\gamma_{s, 0} h_{s, t}+\varepsilon_{s, t} \\
& h_{s, t}=\beta_{s, 0}+\beta_{s, i} \sum_{i=1}^{p} \varepsilon_{s, t-i}^{2}+\gamma_{s, j} \sum_{j=1}^{q} h_{s, t-j} \\
& \varepsilon_{s, t} \mid \Omega_{s, t-1} \sim N\left(0, h_{s, t}\right)
\end{aligned}
$$

where the variables in the mean equation (1) are as follows: $r_{s, t}$ is the market return at time $t$, $x_{s, k}$ are the set of $k$ natural disaster factors expected to influence $r_{s, t}, h_{s, t}$ measures the return volatility or risk of the market portfolio $s$ at time $t$, and $\varepsilon_{s, t}$ is the error term which is normally distributed with zero mean and a variance of $h_{s, t}$, as described by the distribution in (3). The sensitivity of the market portfolio $s$ at $t$ to the natural disaster factors is measured by the $n$ parameters of $\alpha_{s, k}$.

The conditional variance $h_{s, t}$ follows the process described in (2) and for the sth market portfolio is determined by the past squared error terms $\left(\varepsilon_{t-1}^{2}\right)$ and past behavior of the variance $\left(h_{t-1}\right), \beta s, 0$ is the time-invariant component of risk for the sth market portfolio, $\beta s_{\imath l}$ are the ARCH parameter(s) and $\gamma_{s, j}$ are the GARCH parameter(s)

\section{$4 \quad$ Empirical results}

Different GARCH-M $(p, q)$ models were initially fitted to the data and compared on the basis of the Akaike Information Criteria and Schwarz Criterion (results not shown) from which a GARCH(1,1) model was deemed most appropriate for modelling the monthly return process for the market returns. Nonetheless, this particular specification has generally been shown to be a parsimonious representation of conditional variance that adequately fits most financial time series.

\section{$<$ TABLE 2 HERE $>$}

The estimated coefficients and standard errors of the GARCH-M(1,1) parameters are presented in Table 2. The upper panel reports the parameters for the mean equation and the lower panel the parameters for the variance equation. Two separate models are estimated where the dependent variable is variously price returns or accumulation returns. The independent variables for both models are common. The independent variables are dummy variables for storms, floods, cyclones, earthquakes, and bushfires, along with state identifiers for New South Wales, Victoria, Queensland, South Australia, Western Australia and Tasmania. 
The natural disaster hypotheses are tested as follows. As a rule, market returns are expected to be lower when a natural disaster or event occurs. While the signs on the estimated coefficients for both price and accumulation returns are mostly negative (with the exception of cyclones for accumulation returns), in no instance are any of these significant at any conventional level. A second hypothesis is a test of the joint hypothesis that the eleven natural disaster and event parameters are significant in influencing market returns. If the null hypothesis is rejected, then market returns are jointly affected by natural events and disasters. However, for neither price (statistic $=-0.928, p$-value $=1.000$ ) or accumulation returns (statistic $=-0.063, p$-value $=1.000)$ is the null hypothesis rejected. We may include that natural events and disasters in Australia exert no systematic influence on market returns.

It is difficult to compare these results as earlier work is concerned solely with the impact on the insurance sector, rather than market wide effects. For example, Shelor et al. (1992) Aiuppa et al. (1993), Lamb (1995), Angbazo and Narayanan (1996) and Cagle (1996) all linked specific natural disasters in the US with negative price reactions for insurers. However, the results of this analysis are suggestive that sector effects are effectively diversified away: natural events and disasters may well be an important pricing factor in insurance sector returns, but not for the market as a whole.

For the remaining coefficients, the coefficient for the ARCH term in the variance equation is always positive and significant, while the coefficient for the GARCH effect in the variance equation is also positive and significant and larger in magnitude than the ARCH effect. This indicates that volatility shocks in the Australian market persist and are more influential than the immediate past shock. Finally, while the relationship between return and volatility in models like this is far from clear empirically, in none of the models is the GARCH variance term in the mean equation significantly negative.

\section{Concluding remarks}

This study presents an analysis of the distributional and time-series properties of returns in the Australian equity market and the impact of natural events and disasters. The data employed consists of daily price and accumulation returns for the market index over the period 1 January 1980 to 30 June 2003. The results indicate that intraday return volatility in the Australian market is best described by a GARCH-M(1,1) specification and that the inclusion of variables for natural events and disasters in the mean equation does not account for any of the variation observed in daily market returns. 
One explanation for this finding is that the impact of natural events and disasters are likely diversified away at the market level. Rather than being a systematically priced market factor, these events and disasters tend to impact only upon particular companies or regional areas as unsystematic or non-market risk. Moreover, the anticipated costs and/or benefits of these events and disasters can be uncertain for relatively long periods of time, and so no immediate impact is felt in the market until further information comes to hand.

Bearing this in mind, there are several ways in which this work could be extended, especially considering the dearth of literature concerning the impact of natural events and disasters in the Australian equity market. One particular problem is that in common with most work in this area the analysis of the effects of natural events and disasters has been made in isolation from other potential impacts, including calendar and macroeconomic announcement effects. Another way in which this work could be extended is to take greater account of the fact that the financial impact of natural events and disasters will clearly vary according to their economic impact. In this manner, a focus on the much smaller number of major disasters and catastrophes may indicate more significant financial influences, particularly if compared across sectors, industries and companies.

\section{References}

Aiuppa, T.A., Carney, R.J. and Krueger, T.M. (1993) 'An examination of insurer stock prices following the Loma Prieta earthquake’, Journal of Insurance Issues, Vol. 16, No. 1, pp. 1-14.

Albala-Bertrand, J.M. (2000) 'Complex emergencies versus natural disasters: An analytical comparison of causes and effects’, Oxford Development Studies, Vol. 28, No. 2, pp. 187-204.

American Academy of Actuaries (2001) Insurance Industry Catastrophe Management Practices, Public Policy Monograph, Washington.

Anderson, D.R. (2000) 'Catastrophe insurance and compensation: Remembering basic principles', $C P C U$ Journal, Vol. 53, No. 2, pp. 76-89.

Angbazo, L.A. and Narayanan, R. (1996) 'Catastrophic shocks in the property-liability insurance industry: Evidence on regulatory and contagion effects’, Journal of Risk and Insurance, Vol. 63, No. 4, pp. 619-637.

Anonymous (2003) Study: Tokyo is riskiest city, Best's Review, May, p. 60.

Antoniou, A. Holmes, P. and Priestley, R. (1998) 'The effects of stock index futures trading on stock index volatility: An analysis of the asymmetric response of volatility to news', Journal of Futures Markets, Vol. 18, No. 1, pp. 151-166.

Borden, S. and Sarker, A. (1996) 'Securitizing property catastrophe risk', Current Issues in Economics and Finance, Federal Reserve Bank of New York, Vol. 2, No. 9, pp. 1-6.

Bureau of Transport Economics (2001) Economic Costs of Natural Disasters in Australia, Bureau of Transport Economics Report No. 103, Canberra.

Cagle, J.A.B. (1996) 'Natural disasters, insurer stock prices and market discrimination: The case of Hurricane Hugo', Journal of Insurance Issues, Vol. 19, No. 1, pp. 53-68.

Chen, A.H. and Siems, T.F. (2002) An empirical analysis of the capital markets' response to cataclysmic events. Paper presented at the DIW Economic Consequences of Global Terrorism Workshop, Berlin, 14-15 June.

Davidson, W., Chandy, P. and Cross, M. (1987) 'Large losses, risk management and stock returns in the airline industry’, Journal of Risk and Insurance, Vol. 54, No. 1, pp. 163-172.

Emergency Management Australia (2003) <http://www.ema.gov.au/> (accessed August 2003). 
Federal Emergency Management Agency (2003) <http://www.fema.gov/> (accessed August 2003).

Fox, R.T. (1995) 'Measuring catastrophic events on operating viability of firms: Hurricane Hugo and Hospitals', International Advances in Economic Research, Vol. 1, No. 3, pp. 251-262.

Fox, R.T. (1996) 'Using intervention analysis to assess catastrophic events on business environment', International Advances in Economic Research, Vol. 2, No. 3, pp. 341-349.

Horwich, G. (2000) 'Economic lessons of the Kobe earthquake', Economic Development and Cultural Change, Vol. 48, No. 4, pp. 521-542.

Jones, G.B. (1999) 'Alternative reinsurance: Using catastrophe bonds and insurance derivatives as a mechanism for increasing capacity in the insurance markets’, CPCU Journal, Vol. 52, No. 1, pp. 50-54.

Lamb, R.P. (1995) 'An exposure-based analysis of property-liability insurer stock values around hurricane Andrew’, Journal of Risk and Insurance, Vol. 62, No. 1, pp. 111-123.

Miller, R. (1991) 'Natural disasters and their impact on insurance companies and financial markets', Journal of International Securities Markets, Vol. 5, No. 1, pp. 185-189.

Shelor, R., Anderson, D. and Cross, M. (1992) 'Gaining from loss: Property-liability insurer stock values in the aftermath of the 1989 California earthquake’, Journal of Risk and Insurance, Vol. 59, No. 3, pp. 476-488.

Skidmore, M. (2001) 'Risk, natural disasters and household savings in a life cycle model', Japan and the World Economy, Vol. 13, No. 1, pp. 15-34.

Skidmore, M. and Toya, H. (2002) 'Do natural disasters promote long-run economic growth?', Economic Inquiry, Vol. 40, No. 4, pp. 664-687.

Sprecher, C. and Pertl, M. (1983) 'Large losses, risk management and stock prices', Journal of Risk and Insurance, Vol. 50, No. 1, pp. 107-117.

Thompson, A.F., Zaman, M.A. and Kirmani, S.N. (1994) Differential analysis of the impact catastrophic loss has on publicly traded property/causality insurers. Paper presented to the $4^{\text {th }}$ AFIR International Colloquium, 20-22 April.

West, J. (2003) Impact of catastrophic loss in insurance security returns. Paper presented to the Business and Economic Society International (BESI) Conference, San Francisco, 24-28 July.

Zeckhauser, R. (1996) 'The economics of catastrophes', Journal of Risk and Uncertainty, Vol. 12, No. 1, pp. 113-140. 
Table 1 Summary statistics of price and accumulation returns and frequency of natural disasters

\begin{tabular}{lrlrrrrr}
\hline & Number & Mean & Std. Dev. & Skewness & Kurtosis & Jarque-Bera & JB p-value \\
\hline Price returns & 6129 & 0.0003 & 0.0095 & -4.9769 & 143.5288 & 5069365.00 & 0.0000 \\
Accumulation returns & 6129 & 0.0005 & 0.0096 & -4.9145 & 142.4131 & 4988957.00 & 0.0000 \\
Storm & 473 & 0.0772 & 0.2669 & 3.1691 & 11.0434 & 26785.74 & 0.0000 \\
Flood & 691 & 0.1127 & 0.3163 & 2.4491 & 6.9982 & 10211.29 & 0.0000 \\
Cyclone & 311 & 0.0507 & 0.2195 & 4.0944 & 17.7641 & 72802.33 & 0.0000 \\
Earthquake & 17 & 0.0028 & 0.0526 & 18.9101 & 358.5910 & 32661492.00 & 0.0000 \\
Bushfire & 820 & 0.1338 & 0.3404 & 2.1518 & 5.6300 & 6497.09 & 0.0000 \\
New South Wales & 603 & 0.0984 & 0.2978 & 2.6972 & 8.2749 & 14539.52 & 0.0000 \\
Victoria & 284 & 0.0463 & 0.2102 & 4.3166 & 19.6331 & 89700.27 & 0.0000 \\
Queensland & 535 & 0.0873 & 0.2823 & 2.9246 & 9.5536 & 19708.84 & 0.0000 \\
South Australia & 127 & 0.0207 & 0.1425 & 6.7297 & 46.2889 & 524902.20 & 0.0000 \\
Western Australia & 679 & 0.1108 & 0.3139 & 2.4804 & 7.1525 & 10690.17 & 0.0000 \\
Tasmania & 113 & 0.0184 & 0.1345 & 7.1601 & 52.2666 & 672323.30 & 0.0000 \\
\hline
\end{tabular}

Table 2 Estimated mean and variance equations for price and accumulation returns

\begin{tabular}{lrrrrrr}
\hline & \multicolumn{5}{c}{ Price returns } & \multicolumn{3}{c}{ Accumulation returns } \\
& Coefficient & Std. error & p-value & Coefficient & Std. error & $p$-value \\
\hline GARCH effect & 2.2904 & 2.7901 & 0.4117 & 1.9298 & 2.8085 & 0.4920 \\
Constant & 0.0004 & 0.0002 & 0.0688 & 0.0006 & 0.0002 & 0.0061 \\
Storm & -0.0002 & 0.0006 & 0.6620 & -0.0005 & 0.0005 & 0.3904 \\
Flood & -0.0002 & 0.0005 & 0.7069 & -0.0004 & 0.0005 & 0.4235 \\
Cyclone & -0.0002 & 0.0006 & 0.6781 & 0.0001 & 0.0006 & 0.8960 \\
Earthquake & -0.0005 & 0.0032 & 0.8724 & -0.0026 & 0.0021 & 0.2075 \\
Bushfire & -0.0002 & 0.0005 & 0.6567 & -0.0006 & 0.0005 & 0.2031 \\
New South Wales & 0.0003 & 0.0005 & 0.5700 & 0.0007 & 0.0005 & 0.1342 \\
Victoria & -0.0002 & 0.0006 & 0.7434 & -0.0001 & 0.0006 & 0.8733 \\
Queensland & -0.0002 & 0.0005 & 0.7685 & -0.0001 & 0.0005 & 0.9137 \\
South Australia & -0.0002 & 0.0007 & 0.7424 & -0.0002 & 0.0007 & 0.7109 \\
Western Australia & 0.0004 & 0.0005 & 0.4628 & 0.0006 & 0.0005 & 0.2229 \\
Tasmania & 0.0010 & 0.0009 & 0.2941 & 0.0007 & 0.0009 & 0.4212 \\
& \multicolumn{7}{c}{ Variance equation } & & & \\
Constant & 0.0000 & 0.0000 & 0.0000 & 0.0000 & 0.0000 & 0.0000 \\
ARCH effect & 0.2335 & 0.0036 & 0.0000 & 0.2390 & 0.0037 & 0.0000 \\
GARCH effect & 0.6405 & 0.0140 & 0.0000 & 0.6319 & 0.0143 & 0.0000 \\
\hline
\end{tabular}

